\title{
Extensor Carpi Radialis Brevis
}

National Cancer Institute

\section{Source}

National Cancer Institute. Extensor Carpi Radialis Brevis. NCI Thesaurus. Code C52911.

A muscle orig inating at the lateral epicondyle of the humerus and inserted at the third metacarpal bone that controls the radial extension and abduction of the wrist. 